\title{
Effect Of Cultural Dimensions On Stock Exchange Investment Decisions In Iran
}

Zahra Amirhosseini, Islamic Azad University, Shahr-e-Qods Branch, Iran Vivian O. Okere, Providence College, USA

\begin{abstract}
The purpose of this study is to analyze the impact of cultural dimensions on personal investment decisions in the Tehran Stock Exchange. The cultural dimensions model was well established by Geert Hofstede (1980). This research tested a main hypothesis and four subsidiary hypotheses. The data was gathered through library methods and questionnaires. The results showed that the main hypothesis which examined whether there is a significant relationship between cultural dimensions and investment decisions in the Tehran stock exchange was confirmed. Subsidiary hypothesis about the relationship between two of Hofstede's cultural dimensions, Power Distance and Individualism, and investment decisions was not confirmed at a meaningful level. However other subsidiary hypothesis of the research based on the relationship between Masculinity and Uncertainty Avoidance and investment decisions was significant at a meaningful level and confirmed.
\end{abstract}

Keywords: Cultural dimensions; Decision Making; Investment; Stock Market

\section{INTRODUCTION}

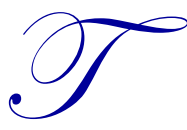

here is a growing interest on the relationship between investment decisions in financial assets and cultural dimensions. Several research studies have analyzed how investors behave when conditions change in financial markets (see Beckman, Menkhoff and Suto, 2008; Hofstede 1980, 2001; Green, Deschamps and Paez 2005). Some of these studies examined the impact of personality, culture and individuals' judgments in investment decisions. In Iran, there is evidence of growth in the capital market primarily because of lately adopted policies which have led to an increase in investments in its financial markets. The purpose for this research is to analyze the effect of cultural dimensions on investors' behavior in the Tehran stock exchange.

The Tehran stock exchange (TSE) located in Tehran, opened in February1967 and is Iran's largest stock exchange. In its first of activity, only six companies were listed in the TSE. Then, government bonds and statebacked certificates were traded in the market. Today, TSE has evolved into a leading emerging market where individual and institutional investors trade securities of over 420 companies representing more than 40 industries with a market capitalization of more than US\$87 billion. Industries such as the automotive, telecommunications, agriculture, petrochemical, mining, steel iron, copper, banking and insurance, financial mediation and others trade shares at the exchange, more than other exchanges in the Middle East countries. TSE is a full member of the World Federation of Exchanges and is a founding member of the Federation of Euro-Asian Stock Exchanges. Between 2002 and 2010, it is reported that the TSE is one of the world's best performing stock exchanges and the return on investments has reached 131.4 percent.

Iran's expanding equity market is opening new opportunities for investors and asset managers. The number of shareholders in the country has almost doubled since 2002 and there are now futures contracts on single stocks and online trading services in the Tehran's stock exchange. The increase in wealth in Iran is attributable to a change in the culture resulting to change in the investment behavior. 
The definition of culture has been of significant interest in financial science, management and psychology. Though Kroeber and Kluckhohn (1952) posited a critical review of culture, this paper is based on Hofstede (1980) comprehensive and empirical understanding of culture from a national perspective. According to Hofstede, culture is defined as collective programming of the mind that is primarily manifested in values and norms, but also more superficially visible in rituals and symbols. Culture is also referred to as the 'software of the mind' (i.e., mental programming), which is stable over time and implies that the same person will consistently display similar behavior under similar situations. Thus, this research paper analyzes Hofstede cultural dimensions and its effect on investments in the Tehran stock exchange. Hofstede cultural dimensions model explains the values of a particular culture and how it affects the workplace, the organization and the behavior of investors. In his view, culture is the common idea of a group's members which distinguishes them from other groups and it is defined as a set of social behavior patterns, beliefs, customs and other human products and intellectual characteristics of a society or nation.

To analyze the effect of cultural factors on investment behavior in Iran, we refer to Hofstede's $(1980,2001)$ cultural dimension model and his country scores or index for Iran. We also account for all four of his original dimensions, namely, Individualism (IDV), Power Distance Index (PDI), Masculity (MAS) and Uncertainty Avoidance Index (UAI). Further explanation of the single dimensions is discussed below.

\section{INDIVIDUALISM}

According to Hofstede, 'Individualism' (IDV) as opposed to 'Collectivism' focuses on the degree of reinforcement of individual or collective achievements and interpersonal relationships. It also refers to the degree of self importance in contrast with the outer network. In cultures characterized as individualistic, it is assumed that people in the first place will think about their welfare and the personal interests of their relatives. A high individualism ranking for a country expresses individuality and individual rights. Conversely, a low individualism ranking for a country implies that the society tend to work as a group and think as a group, and any given individual will be more likely to sacrifice his or her personal gains for the benefit of the greater group. Based on Figure 1, Hofstede's ranking of Individualism for Iran is at about 38 on a maximum scale of 100, relatively lower than the other cultural factors.

\section{POWER DISTANCE}

'Power Distance' (PDI) takes into account the extent of inequality among members of a country's society. It reveals the degree of inequality in power, wealth and prestige and the tolerance of the inequality gap in the country. While this dimension is harder to measure than Individualism, the dimension also reveals the social influence of the 'powerful and wealthy' in the country. In high PDI countries, it is common to assume that there are gender and class differences amongst the people because they are not born to be equal; hence they are not identical and each one compared to others differently utilizing one's physical and mental abilities. Thus, a high Power Distance will indicate that there is inequality in the society due to power attained by wealth or prestige or status and this is an acceptable norm based on long term orientation. Power and inequality, of course, are extremely fundamental facts of any society and most scholars are aware that 'all societies are unequal, and some are more unequal than others'. This phenomenon is typical in cultures governed by a hierarchical or bureaucratic system. Different from the dimension of Individualism and with respect to Iran, PDI is ranked second (with a rank at about 53 on a maximum scale of 100) to the highest of the four of Hofstede's cultural dimensions, with the highest being 'Uncertainty Avoidance' index; see Figure 1.

\section{MASCULINITY}

The third of Hofstede's cultural dimensions, namely, 'Masculinity' is the extent of gender differentiation and traditional role models. While Masculinity in Iran has a rank of about 40 on a maximum scale of 100, it refers to the distribution of roles between the genders which is another fundamental issue for any society to which a range of solutions are found. In Masculinity societies, the natural difference between a man and a woman determines the social role for them; people are expected to be resolute, ambitious and competing and strive for financial and nonfinancial success. In such societies, men garner more respect than their female counterpart, are more influential and possess authority and power. Being male has a systematic career advantage for achievement and greatness. 
Contrarily, women are expected to be home makers, nurture and support children and the elderly. In general, a Masculinity society is of such where men have the right of assertion, acquire and possess money, properties and assets. Conversely in a femininity society, the primary focus is centered on the issue of relations and in sum the issue of life quality and observance of other people's right is of high importance.

\section{UNCERTAINTY AVOIDANCE}

The last of Hofstede's cultural dimensions, Uncertainty Avoidance, (UAI) discusses the society's coping mechanisms with uncertainty. In other words, it refers to "a society's tolerance for uncertainty and ambiguity". It reflects the extent to which members of a society attempt to cope with anxiety by minimizing uncertainty. Hofstede (2001) refrains from equating Uncertainty Avoidance to risk avoidance. While risk is the quantified uncertainty of a specific event with assigned probabilities and outcomes, uncertainty (alone) cannot be quantified and has a more diffuse outcome. UAI ranking for Iran is at about 54 out of a maximum scale of 100 ..

People in cultures with high uncertainty avoidance tend to be more emotional and try to minimize the occurrence of the unknown and unusual circumstances by carefully planning and implementing rules, laws and regulations. In contrast, low uncertainty avoidance cultures accept and feel comfortable in unstructured situations or changeable environments and try to have as few rules as possible. People in latter cultures tend to be more pragmatic and are more tolerant of change.

In general, Hofstede's research on Iran showed Uncertainty Avoidance (UAI) and Power Distance (PDI) as their highest cultural dimensions. It should be noted that both these dimension rankings are lower in many other Muslim countries. However, with the overthrow of the Shah in January of 1979, and the subsequent re-emergence into Islamic Fundamentalism, the current Hofstede dimensions for Iran may conform more closely with other Muslim countries that have lower Uncertainty Avoidance and Power Distance rankings.

We deduce that Iran's highest ranking of Uncertainty Avoidance indicates the society's low level of tolerance for uncertainty. In an effort to minimize or reduce this level of uncertainty, strict rules, laws, policies, and regulations are adopted and implemented. The ultimate goal of 'this population' is to control everything in order to eliminate or avoid the unexpected. As a result of this high Uncertainty Avoidance characteristic, the society does not readily accept change and is very risk averse.

The high Power Distance (PDI) ranking is indicative of a high level of inequality of power and wealth within the society. This condition is not necessarily subverted upon the population, but rather accepted by the society as their cultural heritage because of the society's long term orientation.

The low ranking on Individuality (IDV) indicates the society is Collectivist as compared to Individualist. As such there exists a close long-term commitment to the immediate family members, extended family, or extended relationships. Loyalty in a collectivist culture is paramount, and overrides most other societal rules and regulations. The society fosters strong relationships where everyone takes responsibility for fellow members of their group.

Nonetheless, most recent research papers have theoretically and empirically analyzed the effect of individualism dimension in cross-cultural psychology (Green et al 2005). However, Chui, Titman and Wei (2005) are the first to apply Hofstede's Individualism index to financial market return patterns. The critics of Hofstede's study and its dimensions have been predominantly anthropologist and sociologists and these groups have criticized Hofstede's methodology of equating nations with culture instead of allowing for maximum diversity within the nation state (see Baskerville, 2003; Ingelhart and Baker, 2000 and Welzel 2003). With these critical arguments in mind, we access Hofstede's research on Iran as an analytical grid with the purpose of analyzing empirical linkages between cultural dimensions and investment activity in Iran. 


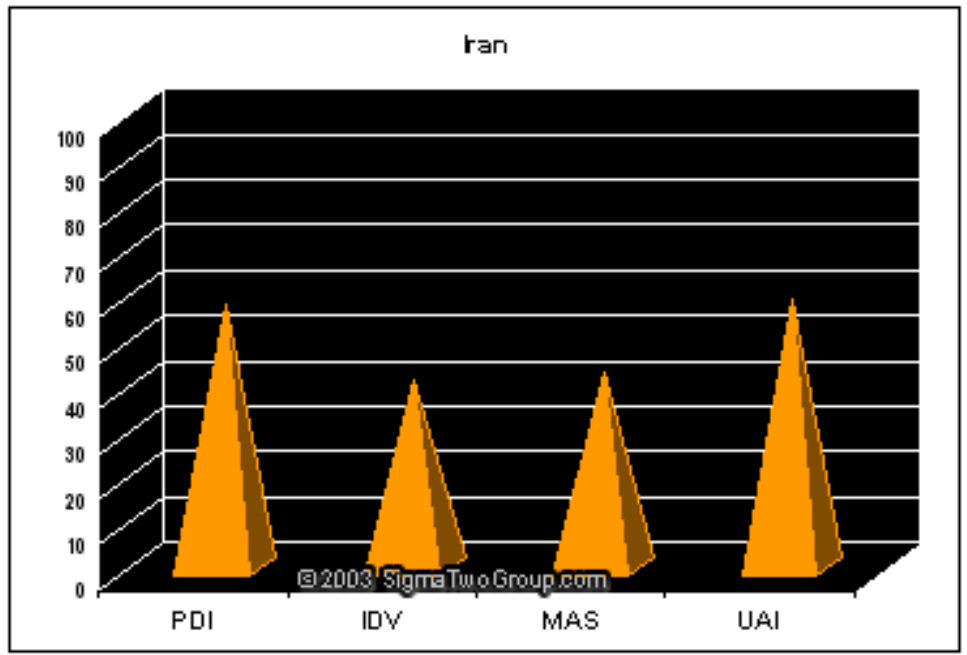

Figure (1): Geert Hofstede Cultural Dimension for Iran

From: Geert Hofstede website

\section{METHODOLOGY AND DATA}

Our analysis of the impact of cultural dimensions on investment decisions in Iran are based on data obtained from Hofstede's questionnaire conducted with shareholders at Tehran's stock exchange. The sample size comprised of 156 investors. The questionnaires were randomly distributed among the sample size with a response rate was 92.3 percent for a total of 144 respondents. Our response rate represent an excellent result compared to the response rate of 47.5 percent of Beckman et al research studies. Most of the respondents are long term shareholders of stocks listed in the Tehran Stock Exchange. They are also inhabitants of Tehran or its suburbs.

The questionnaire was divided into four sections. Response to questions of Individualism versus Collectivism indicates that shareholders depict a cultural balance between both dimensions, while the response to questions on Power Distance shows that Power Distance in the society reveals a dominant state of inequality. However and surprisingly, the response to the cultural dimension of Masculinity- femininity suggests femininity influences of the sample of shareholders' group under study. Finally, with regard to the Uncertainty Avoidance, the response to the questions suggests that the statistical society is Uncertainty Avoidance.

\section{HYPOTHESIS}

\section{Main Hypothesis:}

There is a significant relationship between cultural dimensions and investment decisions in the Tehran Stock Exchange.

\section{Subsidiary Hypothesis:}

H1: There is a significant relationship between Power Distance and investment decisions in the Tehran Stock exchange.

H2: There is a significant relationship between Individualism and investment decisions in the Tehran Stock exchange.

H3: There is a significant relationship between Masculinity and investment decisions in the Tehran Stock exchange.

H4: There is a significant relationship between Uncertainty Avoidance and investment decisions in the Tehran Stock exchange. 


\section{Hypothesis Testing:}

Main hypothesis Testing:

There is a significant relationship between cultural dimensions and investment decisions in the Tehran Stock exchange.

$H_{O}$ : There is no relationship between the group of fewer than 3 investors and the group of more than 3 investors.

$H_{1}$ : There is relationship between the group fewer than 3 investors and the group more than 3 investors.

The results are classified as two groups based on Likert Scale ranking of $>3$ and $\leq 3$.

$\left\{\begin{array}{l}H_{O}: \rho \leq 0.6 \\ H_{1}: \rho>0.6\end{array}\right\}$

We developed 25 questions to gather the data and measured the binominal test for the 25 questions. Based on the p-value of less than 0.05 and (significant level $=0.000$ ), it can be inferred that the null hypothesis is rejected at $\alpha=0.05$. Thus, with $95 \%$ confidence it can be stated that there is a significant relationship between cultural dimensions and investment decisions in the Tehran Stock exchange.

\section{Sub-Hypothesis Testing:}

First sub-hypothesis:

There is a significant relationship between Power Distance and investment decisions in the Tehran Stock exchange.

$H_{O}$ : There is no relationship between the group of fewer than 3 investors and the group more than 3 investors.

$H_{1}$ : There is relationship between the group of fewer than 3 investors and the group more than 3 investors.

The results are again classified as two groups based on Likert Scale ranking of $>3$ and $\leq 3$.

$\left\{\begin{array}{l}H_{O}: \rho \leq 0.6 \\ H_{1}: \rho>0.6\end{array}\right\}$

In Table 1, this research study posits that the p-value is greater than 0.05 (significant level $=0.934$ ). Therefore the null hypothesis is confirmed at $\alpha=5 \%$; thus, with $95 \%$ confidence it can be said that there is no significant relationship between Power Distance dimension and investment decisions in the Tehran stock exchange.

Table 1: Binomial Testing

\begin{tabular}{|c|c|c|c|c|c|}
\hline & Category & $\mathbf{N}$ & Observed Prop & Test Prop & Asymp. Sig. (2-tailed) \\
\hline $\begin{array}{c}\text { MAS } \\
\text { Group } 1 \\
\text { Group } 2 \\
\text { Total }\end{array}$ & $\begin{array}{l}3 \leq \\
>3\end{array}$ & $\begin{array}{c}91 \\
53 \\
144\end{array}$ & $\begin{array}{l}0.63 \\
0.37 \\
1.00\end{array}$ & 0.60 & 0.002 \\
\hline $\begin{array}{cc}\text { IDV } & \\
& \text { Group 1 } \\
& \text { Group 2 } \\
& \text { Total } \\
\end{array}$ & $\begin{array}{l}3 \leq \\
>3\end{array}$ & $\begin{array}{c}79 \\
65 \\
144\end{array}$ & $\begin{array}{l}0.55 \\
0.45 \\
1.00\end{array}$ & 0.60 & 0.279 \\
\hline $\begin{array}{cc}\text { UAI } & \\
& \text { Group 1 } \\
& \text { Group } 2 \\
& \text { Total }\end{array}$ & $\begin{array}{l}3 \leq \\
>3\end{array}$ & $\begin{array}{c}15 \\
129 \\
144\end{array}$ & $\begin{array}{l}0.10 \\
0.90 \\
1.00\end{array}$ & 0.60 & 0.000 \\
\hline $\begin{array}{cc}\text { PDI } & \\
& \text { Group } 1 \\
& \text { Group 2 } \\
& \text { Total }\end{array}$ & $\begin{array}{l}3 \leq \\
>3\end{array}$ & $\begin{array}{c}71 \\
73 \\
144\end{array}$ & $\begin{array}{l}0.49 \\
0.51 \\
1.00\end{array}$ & 0.60 & 0.934 \\
\hline
\end{tabular}

(C) 2012 The Clute Institute http://www.cluteinstitute.com/ 
Second sub-hypothesis:

There is a significant relationship between Individualism and investment decisions in the Tehran Stock exchange.

$H_{O}$ : There is no relationship between the group of fewer than 3 investors and the group more than 3 investors.

$H_{1}$ : There is relationship between the group of fewer than 3 investors and the group more than 3 investors.

$$
\left\{\begin{array}{l}
H_{O}: \rho \leq 0.6 \\
H_{1}: \rho>0.6
\end{array}\right\}
$$

Given that the mean is equal to 2.99 , it can be said that the shareholders are almost in cultural balanced state in this regard. As a result on Table 1, given the p-value which is more than 0.05 (significant level $=0.279$ ), it can be stated that the null hypothesis at $\alpha=5 \%$ is confirmed. Therefore with $95 \%$ confidence it can be stated that there is no significant relationship between Individualism and investment decisions in the Tehran Stock exchange.

Third sub-hypothesis:

There is a significant relationship between Masculinity and investment decisions in the Tehran Stock exchange.

$H_{O}$ : There is no relationship between the group of fewer than 3 investors and the group more than 3 investors.

$H_{1}$ : There is relationship between the group of fewer than 3 investors and the group more than 3 investors.

$$
\left\{\begin{array}{l}
H_{O}: \rho \leq 0.6 \\
H_{1}: \rho>0.6
\end{array}\right\}
$$

The mean is equal to 2.86 which suggest femininity of the society. Based on Table 1 and the p-value of less than 0.05 (Sig. $=0.002$ ), it can be said that the null hypothesis is rejected at $\alpha=0.05$. Therefore, with $95 \%$ confidence it can be stated that there is a significant relationship between Masculinity influences and investment decision in Tehran Stock exchange.

Fourth sub-hypothesis:

There is a significant relationship between Uncertainty Avoidance and investment decision in Tehran Stock exchange.

$$
\left\{\begin{array}{l}
H_{O}: \rho \leq 0.6 \\
H_{1}: \rho>0.6
\end{array}\right\}
$$

The mean is equal to 4.08, it can be said that the investors' Uncertainty Avoidance is high. Given the result on Table 1 and the p-value of less than 0.05 , it can be said that the null hypothesis is rejected at $\alpha=5 \%$. Thus, with $95 \%$ confidence it can be said that there is a significant relationship between investors' Uncertainty Avoidance and their investment decisions in the Tehran Stock exchange.

\section{Other Findings:}

An alternative statistical test is the Spearman test. This test measures the relationship between the four tested hypotheses. If the significant level is less than 5\%, the null hypotheses suggesting absence of any relationship at $95 \%$ confidence is rejected and it can be stated that there is a significant relationship between two of cultural dimensions analyzed. Table 2 shows the Spearman test and the correlation results. 
Table 2: Spearman Test

\begin{tabular}{|l|c|c|c|c|}
\hline & IDV & UAI & PDI \\
\hline MAS Correlation Coefficient & & $0.198^{*}$ & 0.019 & $0.257^{* *}$ \\
Sig. (2-tailed) & & 0.017 & 0.817 & 0.002 \\
N & & 144 & 144 & $0.226^{* *}$ \\
IDV Correlation Coefficient & $0.198^{*}$ & & $0.176^{*}$ & 0.006 \\
Sig. (2-tailed) & 0.017 & & 0.035 & 144 \\
N & 144 & & $0.470^{* *}$ \\
UAI Correlation Coefficient & 0.019 & $0.176^{*}$ & & 0.000 \\
Sig. (2-tailed) & 0.817 & 0.035 & & 144 \\
N & 144 & 144 & \\
PDI Correlation Coefficient & $0.257^{* *}$ & $0.226^{* *}$ & $0.470^{* *}$ & \\
Sig. (2-tailed) & 0.002 & 0.006 & 0.000 & 144 \\
N & 144 & 144 & & \\
\end{tabular}

The above results show significant correlation between Masculinity (MAS) and Power Distance (PDI) and MAS and Individualism (IDV). Individualism is correlated with PDI, MAS and Uncertainty Avoidance (UAI). Uncertainty Avoidance is correlated with PDI and IDV. Power Distance is correlated with UAI and with MAS and IDV.

While Power Distance is correlated with the three dimensions of Masculinity, Individualism and Uncertainty Avoidance, Individualism is correlated with the three other dimensions Masculinity, Uncertainty Avoidance and Power Distance. Finally, the paper finds no relationship between Masculinity and Uncertainty Avoidance.

Another research cited in this paper is the Schleifer (2000) test which shows that there is a relationship between individuals' personality traits (level of education, occupation, age and sex) and the 4 hypotheses analyzed. However, this research paper finds no association between investors' education, occupation, age and sex and their decision to invest in the Tehran stock exchange.

\section{CONCLUSION AND RECOMMENDATION}

This paper analyzed the effect of Hofstede's cultural dimensions on investment decisions in the Tehran stock exchange. We find that Power Distance, Masculinity and Uncertainty Avoidance affect the investment behavior of investors in the Tehran stock exchange. However, there is no significant relationship between Individualism and investment decisions. The effect of these cultural dimensions on investment behavior is expected to change over time because these cultural influences are affected by other macroeconomic, political and environmental factors.

Beginning with the Individualism dimension, we find that individual investors in Iran follow market trends loosely because of a stronger evidence of Collectivism than Individualism in the society. Loyalty in a collectivist culture prevails and fosters strong relationships where everyone takes responsibility for fellow members of their group. The influences of collectivism can be seen as a way in which members of the society learn from others. As such, the cultural dimension of Individualism contributes the a better understanding of collectivism. Our result also confirms that Power Distance is a strong determinant of investment decisions because age, wealth and status influence the strategic behavior of investors, especially risk taking, and thus may lead to a more conservative portfolio allocation. Due to the inequality between low and high income groups, the managers of the stock exchanges and other respective authorities should ease the condition for investment for the society's low income groups, even when the amount invested is considered insignificant.

Masculinity affects investment decisions significantly. Iran is a more masculine-driven country meaning a higher degree of representation of the male gender. This is important because men are assumed to be more aggressive and often less risk averse, and as a result, a man's investment decision is different from that of a woman. Therefore, one can posit that more masculine societies are characterized by a more aggressive investment style leading to higher turnovers and asset volumes. 
Finally, the fourth cultural dimension of Uncertainty Avoidance also affects investment decisions. Our empirical analysis and results show that the first priority of investors of the stock exchange is uncertainty avoidance. Therefore, managers of the stock exchanges should prepare the necessary grounds and conditions to resolving this kind of ambiguities for investments on the stock exchange.

We conclude that variations in cultural dimensions will translate into different investment behavior. Unfortunately, cultural influences do not always affect investor behavior to the same extent in the same direction. One can therefore argue that the traditional capital market theory does not explain cultural norms and investor behavior. Thus, cultural dimensions are important factors that need to be incorporated in investment theory and management. Finally, the relationship between individuals' personality traits and the research hypotheses which validate the theory suggest that some shareholders purchase shares of stock as a result of the psychological atmosphere created (by a special group) in the market without knowledge of the investment. Therefore, the stock exchange may consider organizing education classes for the stock exchanges' shareholders in order to enhance their financial knowledge and analytical power. Among other actions that may be considered by the stock exchange and other respective authorities is the creation and improvement of suitable cultural grounds so as to promote investment by individuals.

\section{AUTHOR INFORMATION}

Zahra Amirhosseini, Assistant Professor, Department of Management, Shahr-e-Qods Branch, Islamic Azad University,Tehran, Iran. E-mail: zamirhosseini@shahryariau.ac.ir

Vivian O. Okere, Professor, Providence College, Providence, Rhode Island. USA. E-mail: vokere@providence.edu (Corresponding author)

\section{REFERENCES}

1. $\quad$ Baskerville, R. F. (2003). "Hofstede never studied culture". Accounting, Organizations and Society. 28, 114.

2. Beckman, D.; Menkoff, L. and M. Suto (2008). "Does culture influence asset managers' views and behavior?". Journal of Economic Behavior \& Organization. 67, 624-643.

3. Chui, A.C.W., Titman, S., and K.C.J. Wei (2005). "Individualism and momentum around the world. AFA 2006 Boston Meetings Paper.

4. Green, E.G.T., Deschamps, J.C., and D. Paez (2005). 'Variations of Individualism and collectivism within and between 20 countries-a typological analysis". Journal of Cross-Cultural Psychology. 36, 321-339

5. Hodge. F. D., (2003). "Investors' Perceptions of Earning Quality, Auditor Independence, and the Usefulness of Audited Financial Information". Accounting Horizons. 17(Supplement), PP. 37-48.

6. Hofstede, G. H (1980) “Culture's Consequences: International Differences in Work Related Values". Sage Publications, Beverly Hills, CA.

7. Hofstede, G. H. (2001). “Culture's Consequences, Comparing Values, Behaviors, Institutions, and Organizations Across Nations", 2nd Edition. Thousand Oaks CA: Sage Publications.

8. Hofstede G. H. (1997). "Cultures and Organizations: Software of the Mind”, New York: McGraw-Hill USA.

9. Inglehart, R. and Baker, W.E.(2000). "Modernization, cultural change and the persistence of traditional values". American Sociological Review. 65. 19-51.

10. Kroeber, A. L., and C. Kluckhohn (1952). Culture: a critical review of concepts and definitions. Papers of the Peabody Museum of American Archaeology and Ethnology. 47, Harvard University, Cambridge, MA.

11. Norman. A.S., (2011). "Financial Analysis as a consideration for Stock Exchange Investment Decisions in Tanzania", Journal of Accounting and Taxation. Vol 3(4). PP. 60-69

12. Shleifer. A. (2000). "Inefficient Markets: An Introduction to Behavioral Finance". Oxford University Press

13. Tehran Stock Exchange Website: www.irbourse.com

14. Welzel, C., Inglehart, R. and Klingemann, H.D. (2003). "The theory of human development: a crosscultural analysis”. European Journal of Political Research. 42, 341-379. 